\title{
COMPARISON OF RADIAL GROWTH RATE OF THE MUTUALISTIC FUNGUS OF ATTA SEXDENS RUBROPILOSA FOREL IN TWO CULTURE MEDIA
}

\author{
Miyashira, C.H. ${ }^{1}$; Tanigushi, D.G. ${ }^{1}$; Gugliotta, A.M. ${ }^{2}$; Santos, D.Y.A.C. ${ }^{{ }^{*}}$ \\ ${ }^{1}$ Departamento de Botânica, Instituto de Biociências, Universidade de São Paulo, São Paulo, SP, Brasil; ${ }^{2}$ Seção de Micologia e \\ Liquenologia, Instituto de Botânica, São Paulo, SP, Brasil.
}

Submitted: December 12, 2008; Returned to authors for corrections: April 26, 2009; Approved: November $07,2009$.

\begin{abstract}
In vitro culture of the mutualistic fungus of leaf-cutting ants is troublesome due to its low growth rate, which leads to storage problems and contaminants accumulation. This paper aims at comparing the radial growth rate of the mutualistic fungus of Atta sexdens rubropilosa Forel in two different culture media (Pagnocca B and MEA LP). Although total MEA LP radial growth was greater all along the bioassay, no significant difference was detected between growth efficiencies of the two media. Previous evidences of low growth rate for this fungus were confirmed. Since these data cannot point greater efficiency of one culture medium over the other, MEA LP medium is indicated for in vitro studies with this mutualistic fungus due its simpler composition and translucent color, making the analysis easier.
\end{abstract}

Key words: leaf-cutting ants, mutualistic fungus growth, mycelial growth, Leucoagaricus, Atta sexdens

\section{INTRODUCTION}

Fungus-growing ants are distributed only in the New World and belong to the monophyletic tribe Attini (Hymenoptera-Formicidae-Myrmicinae), which is composed of 12 genera and approximately 210 species.

Among all attine, usually referred to as fungus-growers, the two most phylogenetically derived genera, Acromyrmex and Atta, are more commonly known as leaf-cutting ants (8). The leaf-cutting ants are an important forest herbivore, exploring a great variety of plants which are used to cultivate a specific basidiomycete fungus (6). Several authors have identified this microorganism as Leucoagaricus gongylophorus
(=Leucocoprinus gongylophorus) based on the morphology of fruit-bodies which grow inside Atta sexdens rubropilosa (2) and Atta cephalotes (10) nests, or using molecular sequences (25). This fungus produces a special mycelia structure called gongylidia, rich in glycogen and used as food for the leafcutting larvae (1).

Leaf-cutting ants and the basidiomycete fungus possess an intrinsic mutualistic relationship, strongly integrated with antibiotic, nutritional and physiological co-dependence. Leafcutting ants protect the mutualistic fungus from parasites and potentials competitors $(7,8)$, while the fungus is an essential food source for the larvae and queen $(17,20)$. Other ants in the nests have plant sap as an important food source (23).

\footnotetext{
*Corresponding Author. Mailing address: Department of Botany, Institute of Biosciences, University of São Paulo, Rua do Matão, 277, CEP 05508-090, São Paulo-SP, Brazil..; E-mail: dyacsan@ib.usp.br
} 
Leaf-cutting ants have been considered a dangerous herbivore to some important crop fields. Several methods have already been proposed for the control of these insects. Since all of them present some environmental disadvantage, continuous search for an effective and less pollutant control method acting directly on ants or on fungal development is the focus of much research $(14,21,22)$.

Studies using mutualistic fungi are difficult due to the very slow fungal growth in culture media $(15,16,21,22)$. For example, the mutualistic fungus of Atta sexdens piriventris reached $57 \mathrm{~mm}$ in diameter after 63 days of experiment with an organic medium called Pagnocca A; 34,4 mm with the medium called V8 juice agar; 46,2 mm with an organic medium called Celulose-asparigine; and $16,8 \mathrm{~mm}$ with the mineral medium called Murashige \& Scoog (15). Such slow growth rates turn the storage very difficult, and the fungus culture is often impregnated with contaminants.

In this paper, two solid culture media, MEA LP and Pagnocca B, were evaluated for the efficiency of in vitro fungal growth promotion. MEA LP culture medium was prepared by combination of two traditional culture media (MEA with yeast addition and MEA peptone). Pagnocca B was first described by Silva-Pinhati et al. (25) for bioassays with the mutualistic fungus of Atta sexdens and consists of a new buffered supplemented formulation of Paggnoca Medium A.

\section{MATERIAL AND METHODS}

Eight leaf-cutting ant nests maintained in laboratory were used as fungi source. Fungi fragments and some ants were removed from each nest and transferred to sterile pots, previously autoclaved at $120^{\circ} \mathrm{C}$ and 1.1 atm (eight fungi matrix). The transport of some ants was crucial for successfully fungi culture, because they are able to clean fungi fragments and stimulate its growth. Small isolated mycelium portions of each matrix were inoculated on Petri dishes containing MEA LP, using a sterile laminar flux chamber, for development of the initials cultures.

Two culture media compositions were tested. The first is a common fungi culture medium containing malt extract combined with yeast and peptone (MEA LP - $20 \mathrm{~g}$ malt extract, $5 \mathrm{~g}$ bacteriological peptone, $2 \mathrm{~g}$ yeast extract, $20 \mathrm{~g}$ agar, distilled water up to $1 \mathrm{~L}$ ). The other culture medium, called Pagnocca B by Silva-Pinhati et al. (26), is composed of $10 \mathrm{~g}$ glucose, $2 \mathrm{~g}$ sodium chloride, $2 \mathrm{~g}$ bacteriological peptone, $10 \mathrm{~g}$ malt extract, $17 \mathrm{~g}$ agar, $20 \mathrm{~g}$ casein hydrolysate, $20 \mathrm{~g}$ soybean flakes, $20 \mathrm{~g}$ oat flakes, $3.8 \mathrm{~g}$ sodium phosphate, $2.5 \mathrm{~g}$ citric acid, distillated water up to $1 \mathrm{~L}$, and $\mathrm{pH}$ adjusted to 5.0. Both MEA LP and Pagnocca B culture media were autoclaved at $120{ }^{\circ} \mathrm{C}$ and $1.1 \mathrm{~atm}$ for $30 \mathrm{~min}$.

Sterile Petri dishes were prepared with $15 \mathrm{~mL}$ of culture medium, and kept in a sterile laminar flow chamber under UV light until culture medium solidification. Five millimeter discs containing the mutualistic fungus from initial cultures were transferred to test Petri dishes and placed in the center. Eight Petri dishes, each corresponding to one fungi matrix, were prepared for both MEA LP and Pagnocca B media. The dishes were incubated in a B.O.D. chamber in the dark at $25{ }^{\circ} \mathrm{C}$ $\left( \pm 1^{\circ} \mathrm{C}\right)$.

Two perpendicular straight lines were drawn on the bottom of each Petri dish. The crossing point coincided with the center of the $5 \mathrm{~mm}$ initial fungi disc. Radial growth measurements were recorded weekly from the edge of the initial inoculum until the extreme area of fungi mycelia development, following the four segments formed by the two perpendicular lines (Figure 1). Data for each week correspond to means of four measurements, each one carried out with one segment.

Bioassays were ended when the fungi mycelia reached the Petri dish wall in any dish. Daily fungal growth rate was calculated for each fungi matrix, and expressed as mm.day ${ }^{-1}$. Student's T test was used to evaluate differences significance of fungal growth rates between the two culture media.

\section{RESULT AND DISCUSSION}

Previous bioassays with traditional in vitro culture medium suggested that MEA LP is more effective regarding the growth promotion of the mutualistic fungus of Atta sexdens development, in comparison with MEA+yeast (MEA LP 
without peptone) or BDA+yeast (10 g dextrose, $20 \mathrm{~g}$ agar, juice from $200 \mathrm{~g}$ potate cooked in $500 \mathrm{~mL}$ water, distilled water up to $1 \mathrm{~L})$ (data not shown). Pagnocca et al. $(21,22)$ and Godoy et al. (11) used a growth medium very similar to MEA LP used at the present research, containing glucose, sodium chloride, bacto-peptona, malt extract and agar. Silva-Pinhat et al. (26) suggested a new growth medium, called Pagnocca B, as the best option for this mutualistic fungus culture. In the present paper, both media MEA LP and Pagnocca B are compared for growth efficiency of in vitro culture of this fungus species. The observation of gongylidia on mycelia fragments by optical microscopy supports the identity of the mutualistic fungus (Leucoagaricus sp) in the in vitro cultures (Figure 2) $(6,13$, 27).

Mean values of total radial growth of mutualistic fungus related to time are presented in Figure 3. Bioassays completion took seven weeks. All MEA LP measurements showed higher values than those of Pagnocca B medium, which were more evident after the $28^{\text {th }}$ day. However, no significant differences ( $\mathrm{p} \leq 0.05)$ were observed of in vitro radial growth of this fungus species. Although the MEA LP values were always higher than those obtained with Pagnocca B, the available data failed to support the hypothesis of better growth promotion of one medium over the other.

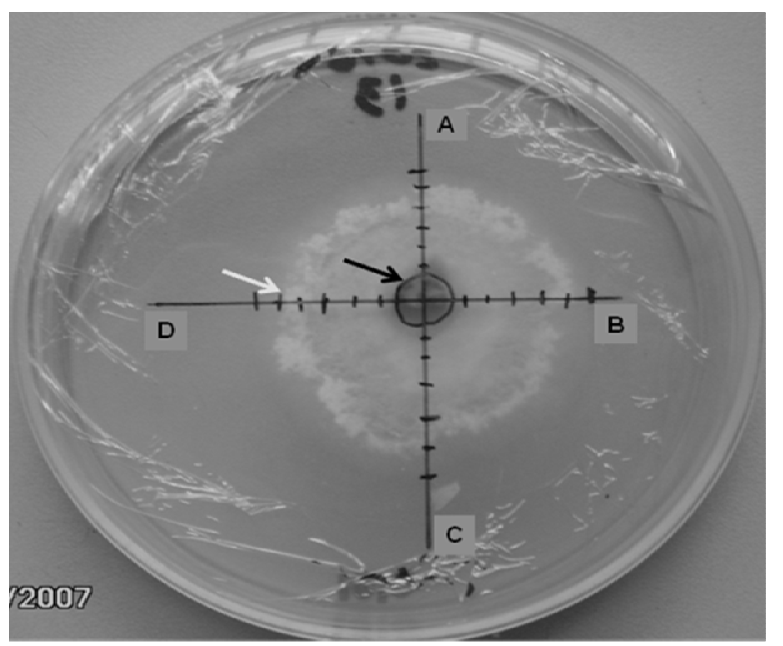

Figure 1. Petri dish used for fungus growth bioassay. Black arrow indicates the edge of initial inoculum. White arrow indicates the edge of fungi radial growth six weeks after bioassay start. Letters A, B, C, $\mathrm{D}$ correspond to the four segments used for growth measurements.
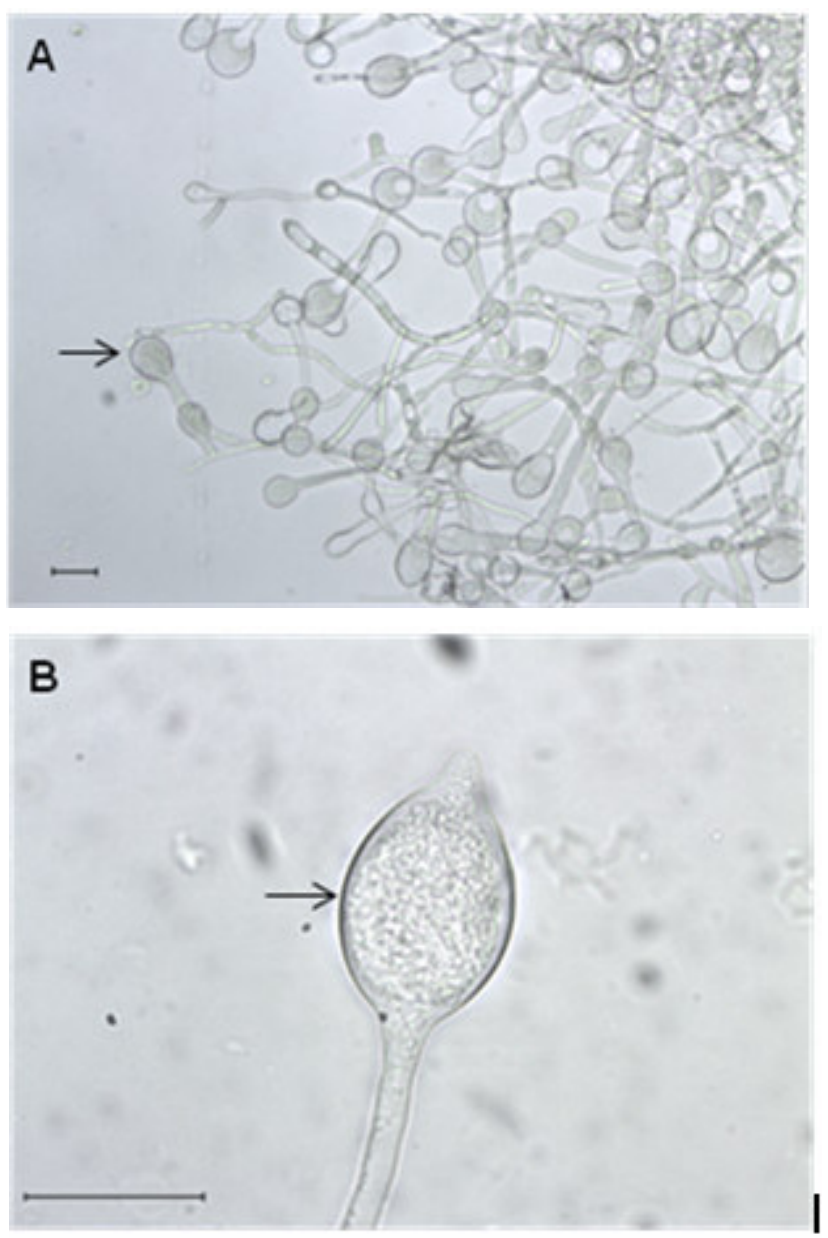

Figure 2. Mycelia detail from mutualistic fungi of Atta sexdens rubropilosa. Enlarged apical structures correspond to gongylidia (arrows). Bars $=40 \mu \mathrm{m}$. (Photo: A. M. Gugliotta).

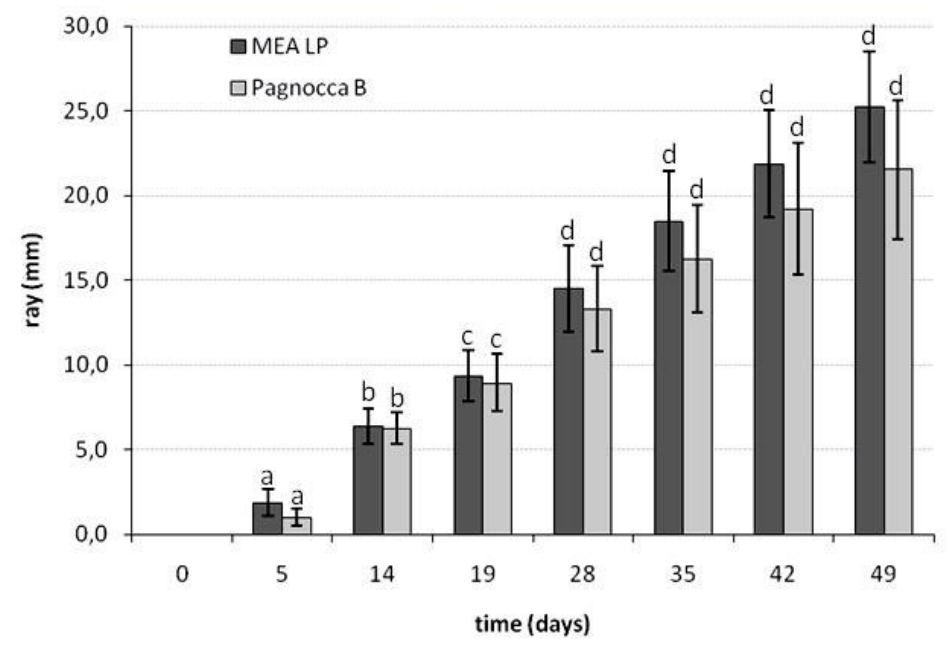

Figura 3. Means and confidence intervals of in vitro radial growth of mutualistic fungus of Atta sexdens rubropilosa in MEA LP medium and Pagnocca B medium ( $n=8)$. Same letter over bars indicates that there is no significant difference by using Student $\mathrm{T}$ test $(\mathrm{P}<0.05)$. 
Based on total radial growth, daily growth rate was calculated for each one of the eight fungus matrices (Table 1). Daily growth rates among MEA LP samples were less variable, in comparison with Pagnocca samples. The standard deviation calculated using the eight MEA LP dish plates was very low. Only one sample presented daily growth rate lower than 0.4 mm.day ${ }^{-1}$ with MEA LP medium (matrix $6=0.380$ mm.day ${ }^{-1}$ ). All other samples presented values between 0.426 mm.day ${ }^{-1}$

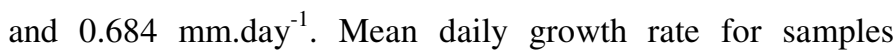
cultivated with Pagnocca B medium was lower than the value obtained for MEA LP, 0.440 mm.day ${ }^{-1}$ and 0.515 mm.day ${ }^{-1}$, respectively. Four of the eight sample matrices presented growth rate lower than 0.4 mm.day ${ }^{-1}$ with Pagnocca B medium. Comparing MEA LP and Pagnocca B values for the same matrix, four of them presented higher MEA LP values (matrices 4, 5, 7 and 8), while the others (matrices 1, 2, 3 and 6) grew better with Pagnocca B. Matrix 8 presented, at the same time, the highest growth rate with MEA LP (0.684 mm.day ${ }^{-1}$ ) and the lowest one with Pagnocca medium $\left(0.316 \mathrm{~mm} \cdot \mathrm{day}^{-1}\right)$.

Table 1. Radial growth rate $\left(\mathrm{mm}^{-d a y^{-1}}\right)$ for each fungi matrix cultivated in MEA LP medium and Pagnocca B medium.

\begin{tabular}{|c|c|c|}
\hline \multirow[b]{2}{*}{$\begin{array}{l}\text { Fungi } \\
\text { matrix }\end{array}$} & \multicolumn{2}{|c|}{ Culture medium } \\
\hline & MEA LP & Pagnocca B \\
\hline 1 & 0.528 & 0.543 \\
\hline 2 & 0.520 & 0.617 \\
\hline 3 & 0.584 & 0.541 \\
\hline 4 & 0.543 & 0.342 \\
\hline 5 & 0.454 & 0.332 \\
\hline 6 & 0.380 & 0.490 \\
\hline 7 & 0.426 & 0.337 \\
\hline 8 & 0.684 & 0.316 \\
\hline mean $\pm \mathrm{sd}$ & $0.515 \pm 0.0957$ & $0.440 \pm 0.1208$ \\
\hline
\end{tabular}

These large differences among matrices could be explained taking into account that the mutualist is clonally propagated by queens that carry a pellet of the fungus in their mouth during their nuptial flight to establish new colonies (1). In addition to vertical propagation from one generation to another, recent research has suggested that horizontal fungi transmission may also happen among ant nests or among close related ant species $(12,19)$.

Students's T test was applied to verify whether there is a significant difference among daily fungal growth rates on petri dishes filled with MEA LP or Pagnocca B media. Since the observed t-value $(\mathrm{T}=1.381)$ is below the absolute $\mathrm{t}$-value $(\mathrm{T}=$ 1.7613), no significant difference has been found between daily growth rates using both MEA LP or Pagnocca B culture media.

The growth rate of Leucoagaricus species, mainly those with mutualistic relationship with leaf-cutting ants, has already been pointed out as very slow. The low growth rate has been considered a limiting factor regarding several experimental analyses $(15 ; 21 ; 22)$. Loeck et al. (16) reported radial growth rate for the mutualistic fungus associated with another leafcutting ant species (Atta sexdens piriventris) with several culture media. The highest value obtained was $56.7 \mathrm{~mm}$ after 49 weeks or 0.165 mm.day ${ }^{-1}$. This value is even lower than those obtained in the present work. Studies carried out with other non-mutualistic basidyomicetes species show values of growth rate at least 2,000 times higher in comparison with the mutualistic fungus used in this study. For example, Matheus

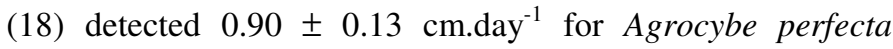

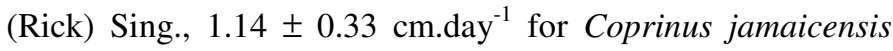

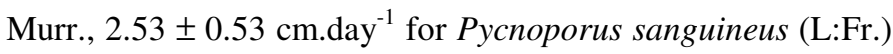
Murr., and $3.77 \pm 0.42 \mathrm{~cm} . d a y^{-1}$ for Phanerochaete chrysosporium Burds. The intrinsic relationship inside higher attine nests could partially account for the low growth rate of the mutualistic fungus. The dynamics of the association between the ants and their fungi are complex, including other organisms such as the filamentous fungus Pseudonocardia (Actinomycetes) which produces antibiotics that inhibits the growth of Escovopsis (a virulent pathogen fungus), aiding in the garden maintenance (8).

Besides culture medium composition, other parameters have already been investigated concerning fungal growth rate improvement. Cazin et al. (5) tested three temperatures for in vitro culture, and observed higher growth rate at $24^{\circ} \mathrm{C}$ than at $30^{\circ} \mathrm{C}$ or $37^{\circ} \mathrm{C}$. Our experiments have been conducted at $25^{\circ} \mathrm{C} \pm$ 
$1^{\circ} \mathrm{C}$, very close to the ideal temperature previously established.

Another problem regarding leaf-cutting ant mutualistic fungus culture is contaminants accumulation. This problem is closely correlated with the low growth rate of Leucoagaricus species in in vitro culture. Although reduced time for bioassays was the focus of some research $(11,21,22)$, no ideal assay time can be defined based on the available data. Even though no contaminants have developed at most dish plates, in some bioassays lasting more than seven weeks changes were noted in the fungus color and in the culture medium, which were determinant for the experiment failure.

Distinct measurement ways have been used for determination of in vitro fungi growth. Although estimative evaluation based on visual observation $(15,22)$ and determination of relative percentage increase in comparison to the initial condition $(9,11,21,24)$ has been successful measurements, such criteria were dependent on the researcher interpretation. The measurement strategy used in the present work achieved more accurate results, since all values were obtained using a measure instrument. Loeck et al. (16) and Borba et al. $(3,4)$ have already employed the same radialgrowth measures to evaluate the growth rate of the mutualist fungus of another leaf-cutting ant species.

Radial-growth rate has been shown to be a good measurement approach, although it does not take into account the fungal vertical growth or the increase of density in the Petri dish. Only radial growth (e.g. horizontal growth) is considered in this method. Notwithstanding the growth rate measurements presented have probably been underestimated, radial-growth use turns the obtained values easier to compare with other results and improve data accuracy.

Finally, since no significant difference was found between both tested culture media (MEA LP and Pagnocca B), none of the media can be considered more efficient than the other for fungal growth promotion. However, MEA LP is pointed out as more convenient, due its simpler composition and visual transparency, turning the radial measurements easier and more precise.

\section{ACKNOWLEDGEMENTS}

The authors thank CAPES for C.H.M. fellowship grant, $\mathrm{CNPq}$ and FAPESP for financial support and Section of Micology and Lichenology of Botany Institute of the Environmental Secretary of the State of São Paulo for providing all conditions for fungi culture.

\section{REFERENCES}

1. Beattie, A.J.; Hughes, L. (2002). Ant-plant interactions. In: Herrera, C. M.; Pellmyr, O. (Eds). Plant-animal interaction. A evolutionary approach. Blackwell Publishing, Oxford. 211-235p.

2. Bononi, V.L.R.; Autuori, M.; Rocha, M.B. (1981). Leucocoprinus gongylophorus (Möller) Heim, o fungo do formigueiro de Atta sexdens rubropilosa Forel. Rickia 9, 93-97.

3. Borba, R.S.; Loeck, A.E.; Bandeira, J.M.; Moraes, C.L.; Centenaro, E.D. (2006). Crescimento do fungo simbionte de formigas cortadeiras do gênero Acromyrmex em meios de cultura com diferentes extratos. Ciência Rural 36(3),725-730.

4. Borba, R.S.; Loeck, A.E.; Branco, J.S.C.; Bonow, J.; Oliveira, A.C. (2008). Pareamento de fungos cultivados por diferentes espécies de formigas cortadeiras no Rio Grande do Sul. Ciência Rural 38(5), 12141219.

5. Cazin Jr., J.; Wiemer, D.F.; Howard, J.J. (1989). Isolation, growth characteristics, and long-term storage of fungi cultivated by Attini ants. Appl. Environ. Microbiol. 55(6), 1346-1350.

6. Chapela, I.H.; Rehner, S.A.; Schultz, T.R.; Mueller, U.G. (1994). Evolutionary history of the symbiosis between fungus-growing ants and their fungi. Science 266, 1691-1694.

7. Currie, C.R.; Mueller, U.G.; Malloch, D. (1999). The agricultural pathology of ant fungus garden. Proceedings of the National Academy of Sciences of the United States of America 96, 7998-8002.

8. Currie, C.R. (2001). A community of ants, fungi and bacteria: a multilateral approach to studying symbiosis. Annu. Rev. Microbiol. 55, 357-380.

9. Fernandes, J.B.; David, V.; Facchini, P.H.; Silva, M.F.G.F.; Rodrigues Filho, E.; Vieira, P.C.; Galhiane, M.S.; Pagnocca, F.C.; Bueno, O.C.; Hebling, M.J.; Victor, S.R.; Santos, A.M.R. (2002). Extrações de óleos de sementes de citros e suas atividades sobre a formiga cortadeira Atta sexdens e seu fungo simbionte. Química Nova 25(6B), 1091-1095.

10. Fisher, P.J.; Stradling, D.J.; Pegler, D.N. (1994). Leucoagaricus basidiomata from a live nest of the leaf-cutting ant Atta cephalotes. Mycol. Res. 98(8), 884-888.

11. Godoy, M.F.P.; Victor, S.R.; Bellini, A.M.; Guerreiro, G.; Rocha, W.C.; Bueno, O.C.; Hebling, M.J.A.; Bacci Jr., M.; Silva, M.F.G.F.; Vieira, P.C.; Fernandes, J.B.; Pagnocca, F.C. (2005). Inhibition of the Symbiotic 
Fungus of Leaf-Cutting Ants by Coumarins. J. Braz. Chem. Soc. 16(3B), 669-672.

12. Hebling, M.J.A.; Bueno; O.C.; Maroti, P.S.; Pagnocca, F.C.; Silva, O.A. (2000). Effects of leaves of Ipomoea batatas (Convolvulaceae) on nest development and on respiratory metabolism of leaf-cutting ants. J. Appl. Entomol. 124, 249-252

13. Hölldobler, B.; Wilson, E.O. (1990). The ants. The Belknap Press of Harvard University Press. Massachussetts. 732p.

14. Howard, J.J.; Cazin J.; Wiemer, D.F. (1988). Toxicity of terpenoid deterrents to the leafcutting ant Atta cephalotes and its mutualistic fungus. J. Chem. Ecol. 14, 59-69.

15. Loeck, A.E.; Pierobom, C.R.; Gusmão, L.G.; Afonso, A.P. (2004). Growth of symbiont fungi of some higher attine ants in mineral medium. Ciência Rural 34(1), 79-82.

16. Martin, M.M.; Carman, R.M.; MacConnel, J.G. (1969). Nutrients derived from the fungus cultured by the fungus-growing ant Atta colombica tonsipes. Annals of the Entomological Society American 62,11-13.

17. Matheus, D.R. (1998). Biorremediação de solos contaminados com compostos organoclorados e biodegradação de hexaclorobenzeno por basidiomicetos brasileiros. (Ph D Tesis. Instituto de Biociências UNESP - Rio Claro). 166p.

18. Monteiro, M.R.; Torkomian, V.L.V.; Pagnocca, F.C.; Vieira, P.C.; Fernandes, J.B.; Silva, M.F.G.F.; Bueno, O.C.; Hebling, M.J.A. (1998). Activity of extracts and fatty acids of Canavalia ensiformis (Leguminosae) against the symbiotic fungus of the leaf-cutting ants Atta sexdens. Anais da Academia Brasileira de Ciências 70(4), 733-736.

19. Quinlan, R.J.; Cherrett, J.M. (1977). The role of substrate preparation in the symbiosis between the leaf cutting ant Acromyrmex octospinosus (Reich) and its food fungus. Ecol. Entomol. 2, 161-170.
20. Pagnocca, F.C.; Ribeiro, S.B.; Torkomian, V.L.V.; Hebling, M.J.A.; Bueno, O.C.; Silva, O.A.; Fernandes, J.B.; Vieira, P.C.; Silva, M.F.G.F.; Ferreira, A.G. (1996). Toxicity of lignans to symbiotic fungus of leafcutting ants. J. Chem. Ecol. 22(7), 1325-1330.

21. Pagnocca, F.C.; Silva, O.A.; Hebling-Beraldo, M.J.; Bueno, O.C.; Fernandes, J.B.; Vieira, P.C. (1990). Toxicity of sesame extracts to the symbiotic fungus of leaf-cutting ants. Bull. Entomol. Res. 80, 349-352.

22. Ribeiro, S.B.; Pagnocca, F.C.; Victor, S.R.; Bueno, O.C.; Hebling, M.J.; Bacci Jr, M.; Silva, O.A.; Fernandes, J.B.; Vieira, P.C.; Silva, M.F.G.F. (1998). Activity of Sesame Leaf Extracts Against the Symbiotic Fungus of Atta sexdens L. Anais da Sociedade Entomológica do Brasil 27(3), 421-426.

23. Silva, A.; Bacci Jr, M; Siqueira, C.G.; Bueno, O.C.; Pagnocca, F.C.; Hebling, M.J.A. (2003). Survival of Atta sexdens workers on different food sources. J. Insect Physiol., 49:307-313.

24. Silva-Pinhati, A.C.O.; Bacci Jr, M.; Hinkle, G.; Pagnocca, F.C.; Martins, V.G.; Bueno, O.C.; Hebling, M.J.A. (2004). Low variation in ribosomal DNA and internal transcribed spacers of the symbiotic fungi of leafcutting ants (Attini: Formicidae). Braz. J. Med. Biol. Res. 37, 1463-1472.

25. Silva-Pinhati, A.C.O.; Bacci Jr, M.; Siqueira, C.G.; Silva, A.; Pagnocca, F.C.; Bueno, O.C.; Hebling M.J.A. (2005). Isolation and Maintenance of Symbiotic Fungi of Ants in the Tribe Attini (Hymenoptera: Formicidae). Neotrop. Entomol. 34(1), 1-5.

26. Siqueira, C.G.; Bacci, Jr, M.; Pagnocca, F.C.; Bueno, O.C.; Hebling, M.J.A. (1998). Metabolism of Plant Polyssacharides by Leucoagaricus gongylophorus, the symbiotic fungus of the leaf-cutting ant Atta sexdens L. Appl. Environ. Microbiol. 64(12), 4820-4822.

27. Weber, N.A. (1966). Fungus-growing ants. Science, 153:587-604. 